\title{
LEVANTAMENTO ARQUITETÔNICO DA ANTIGA ESTAÇÃO FERROVIÁRIA DE PRESIDENTE BERNARDES - SP
}

Anderson de Oliveira Ferreira Lima, Bruno Rafael Fernandes, Lívia de Oliveira Ferreira e Silva, Yeda Ruiz Maria

Universidade do Oeste Paulista - UNOESTE. Curso de Arquitetura e Urbanismo, Presidente Prudente - SP. E-mail: yedarm@hotmail.com

\section{RESUMO}

A presente pesquisa tem como objetivo o levantamento histórico e arquitetônico do edifício da antiga Estação Ferroviária da cidade de Presidente Bernardes - SP, a fim de embasar o desenvolvimento do Inventário de Bens Culturais. O edifício é de importância histórica e cultural, pois foi através da ferrovia que frentes pioneiras desbravaram o sertão paulista - trata-se de um marco da colonização nessa região. As ferrovias, de modo geral, possuem importância singular no processo de desenvolvimento de muitas cidades brasileiras, pois por elas "chegou" o desenvolvimento político, econômico e social. Para o cumprimento dos objetivos, foram realizadas pesquisas bibliográficas e documentais sobre a história da ferrovia no Estado de São Paulo, especialmente em sua porção oeste, e de questões sobre patrimônio cultural; verificando-se ainda, junto às bibliotecas, museus e demais órgãos da região a existência de acervo histórico, bem como levantamentos in loco dos edifícios do complexo ferroviário na referida cidade.

Palavras-chave: Estação Ferroviária. Patrimônio Cultural (Ferroviário). Inventário. Preservação. Presidente Bernardes - SP.

\section{ARCHITECTURAL SURVEY OF THE FORMER RAILWAY STATION OF PRESIDENTE BERNARDES - SP}

\section{ABSTRACT}

This research aims to the historical and architectural survey of the building of the former railway station of the city of Presidente Bernardes - SP, in order to base the development of the Inventory of Cultural Property. The building is of historical and cultural importance, because it was through the railroad pioneer fronts paved the São Paulo hinterlands - this is a hallmark of colonization in this region. The railroads, in general, have unique importance in the development process of many brazilian cities, because for them "arrived" political, economic and social development. To achieve the goals, bibliographical and documentary research on the history of the railroad in the State, especially in its western portion, and on cultural heritage issues were conducted; checking up yet, next to libraries, museums and other agencies the existence of historical records, as well as on-site surveys of buildings of the railway complex in that city.

Keywords: Railway Station. Cultural Heritage (Rail). Inventory. Preservation. Presidente Bernardes - SP. 


\section{INTRODUÇÃO E JUSTIFICATIVA}

Em meados do século XIX, a ferrovia era a melhor alternativa para a comunicação e o desenvolvimento do Brasil, fundamental para a economia nacional e gerando grandes mudanças no sistema de transporte, principalmente no território paulista (BEM, 1998). A ferrovia provocou na região da Alta Sorocabana, o surgimento da função urbana, permitindo assim a exploração do território despovoado, com transformação social e espacial, além do impulso econômico (PUPIM, 2009; PASSARELLI, 2006).

As ferrovias tiveram papel de destaque no desenvolvimento do interior paulista (KUHL, 1998, p. 129), o que se verificou, principalmente, a partir de meados do século XIX, com a riqueza gerada pelo café e a chegada da linha férrea por meio da Companhia da Estrada de Ferro Sorocabana através da expansão de sua linha-tronco, por volta de 1922 (GIESBRECHT, 2014). Após anos de funcionamento, passaram por um processo de declínio, e foram privatizadas, estando hoje sob a concessão da América Latina Logística (ALL). Um dos principais motivos dessa decadência foi a diminuição de investimentos no setor, impossibilitando-a de competir com o transporte rodoviário. Logo, a degradação do patrimônio ferroviário se tornou evidente e hoje se encontra totalmente abandonado, deteriorado e com o sucateamento de sua malha. Em nenhuma destas etapas, o patrimônio de interesse cultural das ferrovias paulistas teve atenção e cuidados visando à preservação de seus valores, o que estimulou o desenvolvimento desta pesquisa (MARQUES, 2009).

A ferrovia representou, portanto, o meio de chegada do desenvolvimento econômico, político e social para as cidades do Oeste paulista, o que justifica o título de patrimônio histórico-cultural para a preservação de sua memória (DEMCZUK; MONASTIRSKY, 2010) - materializada, além da linha férrea, principalmente pelas edificações de suas antigas estações.

Os patrimônios culturais - bens materiais e imateriais - representam a memória de uma sociedade (LEMOS, 2000), proporcionando aos seus membros um poder de pertencimento e de construção da identidade cultural. Vale pontuar que o patrimônio - os lugares históricos, estilos arquitetônicos, artes tradicionais, festas, costumes e tradições - deve ser preservado para que não perca o seu valor e seja repassado às gerações futuras (DEMCZUK; MONASTIRSKY, 2010).

Neste contexto tem-se como objeto de estudo a antiga Estação Ferroviária da cidade de Presidente Bernardes- SP, pertencente anteriormente à Estrada de Ferro Sorocabana e hoje à municipalidade (decreto no 1965/1998). Apesar de abrigar o uso atual de núcleo cultural, isso não garante a preservação integral e a manutenção do caráter da antiga estação ao longo do tempo, pois 
não possui lei/decreto municipal que reconheça seu valor e assegure a preservação e proteção, verificando-se a necessidade da proposta de tombamento desse exemplar material/arquitetônico do período do auge ferroviário da região.

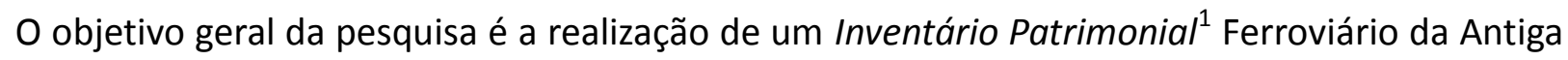
Estação da cidade, a fim de verificar seu potencial histórico-cultural. Pretendeu-se a realização de pesquisa histórica e levantamento bibliográfico, bem como a verificação do estado de conservação das edificações - estação, armazém, pátios, habitações e seu entorno - e, por fim, as condições do patrimônio ferroviário em relação a uma proposta de reciclagem arquitetônica, partindo-se para uma intervenção mais adequada.

\section{METODOLOGIA}

A metodologia da pesquisa partiu de um levantamento bibliográfico buscando o aprofundamento acerca dos temas relacionados à história da ferrovia no Estado de São Paulo e sua porção oeste, bem como do patrimônio histórico, turístico e cultural dos exemplares ferroviários. Tais materiais foram levantados junto às bibliotecas universitárias e do município, Prefeitura e demais órgãos que disponibilizaram acervo histórico. Também foram coletadas informações sobre a história da cidade de Presidente Bernardes - SP e sua relação com o povoamento da região do Oeste Paulista, além de dados cedidos pelo Ministério Público Estadual, a fim de complementar os dados do Inventário Patrimonial - objetivo final desta pesquisa.

O mapeamento realizado a partir de pesquisa e documentação, juntamente com o levantamento in loco dos edifícios do complexo ferroviário, propõe elaborar um instrumento que viabilize a catalogação do patrimônio histórico e artístico relativo à ferrovia e ao edifício da antiga estação da cidade.

\section{PRESIDENTE BERNARDES E A ANTIGA ESTAÇÃO}

A implantação da linha férrea de Presidente Bernardes - SP e a subseqüente construção do edifício da antiga estação - inaugurada em fins da década de 1919 - foram determinantes para a

\footnotetext{
${ }^{1}$ Inventário Patrimonial - "discriminação organizada e analítica de todos os bens e valores do patrimônio num determinado momento", considerando-se os seguintes itens: história da edificação, técnicas construtivas, plantas e/ou fotos, estado de conservação e usos. Esse "instrumento de identificação, avaliação e registro de bens (móveis ou imóveis) de interesse de preservação é uma ferramenta complementar ao tombamento e indispensável para a proteção do patrimônio cultural de uma nação". Inventário Nacional de Bens Imóveis - Sítios Urbanos (INBI-SU). IPHAN, RJ, 2000.
} 
origem do povoado, cujo loteamento iniciou-se em 1920. (PREFEITURA MUNICIPAL, 2006). O traçado inicial do núcleo urbano ficou a cargo de um engenheiro ligado à companhia ferroviária atuante na região e verifica-se ainda que a estruturação da malha da cidade se deu ao longo dos limites da estrada de ferro. A estação foi incentivada pela passagem da estrada de ferro que chegava ao mesmo período na região, cuja instalação se deu por parte da Companhia Ferroviária Sorocabana (SANTOS, 2000).

Fechada e desativada em fins de 1990 depois de quase oito décadas, sendo o palco de idas e vindas de pessoas e mercadorias, a estação passa a ser um local esquecido e abandonado. Contudo, quase uma década se passa e este ponto de referência e importância cultural ressurge, por volta dos anos 2000 - mesmo com as inadequadas transformações e intervenções do ponto de vista arquitetônico e de restauração - dando abrigo ao novo uso de centro cultural, mantido até o presente momento (GIESBRECHT, 2014).

A grande importância da estação ferroviária para a cidade estende-se até os dias de hoje, através das práticas sociais e comunitárias observadas em suas dependências e entorno, mesmo que o potencial desse complexo não é explorado em sua totalidade.

O conjunto dos edifícios da antiga estação - compreendendo alguns equipamentos de cultura, lazer e esportivos - é frequentemente utilizado por relativa parcela da população. Destaca-se aqui o edifício secundário que abriga salas de música que dão suporte ao Projeto Guri, destinado ao ensino musical de crianças, adolescentes e jovens; bem como a importância da sala de cinema existente na edificação principal, cujo uso é destinado para eventos e reuniões de natureza diversa (Figura 1).

A edificação principal, caracterizada por forma simétrica tem seu volume ladeado em sua elevação principal por um pátio, uma via de passagem e praça ajardinada; já sua face de frente aos trilhos da linha férrea, tem em sua extensão a antiga plataforma de embarque/desembarque de passageiros e mercadorias. Os acessos atuais à edificação se dão pelas duas grandes portas da face principal (ambas completadas por um conjunto de escadas e rampas) - uma mais ao centro do volume dá acesso ao setor dos usos culturais, e a outra mais na porção esquerda, adentrada ao provisório uso do Departamento de Transporte Escolar da Prefeitura. Outras duas portas menores localizadas nas faces mais estreitas da edificação, à esquerda e à direita, servem de acesso de funcionários do referido departamento e saída de emergência do auditório, respectivamente. A plataforma é constituída por piso de nível elevado em relação à linha férrea, cujo embasamento é formado por alvenaria de pedras; 
os pilares que sustentam sua cobertura - atualmente de telhas onduladas de fibrocimento - são de perfis de ferro de mesmo formato dos trilhos.

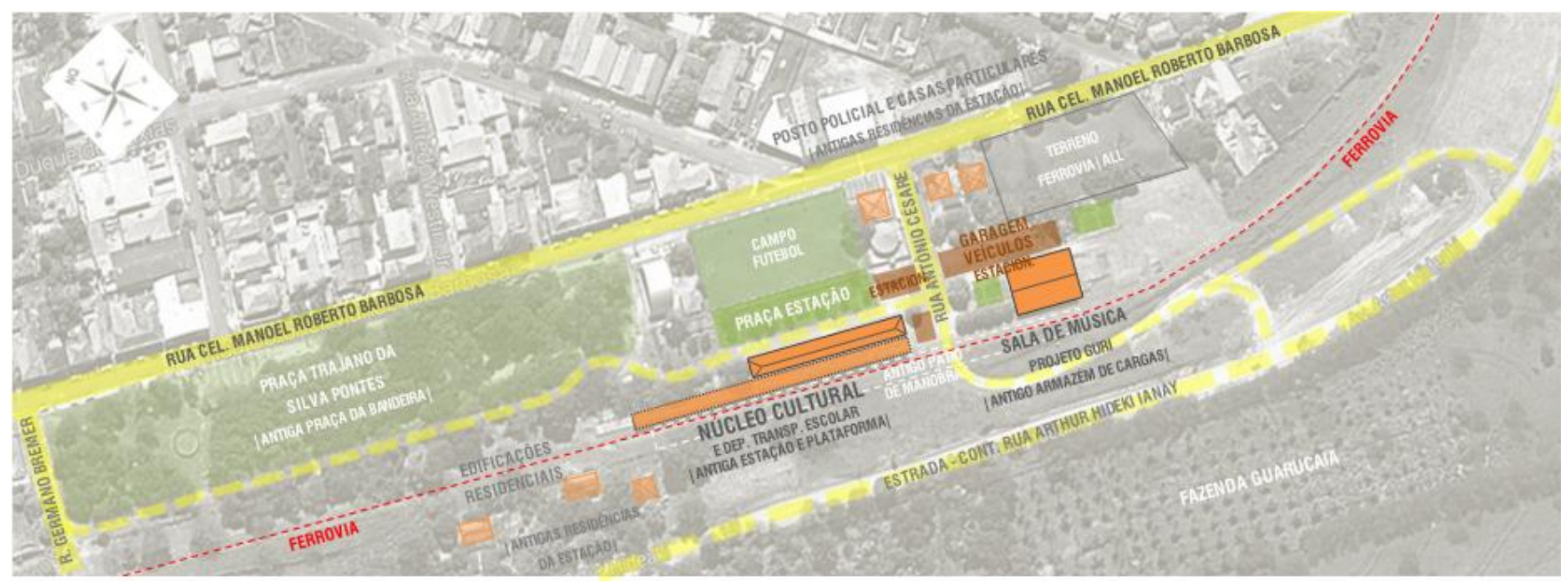

Figura 1. Implantação atual da Estação Ferroviária de Presidente Bernardes - SP Fonte: Google Maps, 2014. Organização: Autores, 2014.

A forma direta de relação das edificações com o público deve-se à inexistência de portões, muros ou gradeamento. A edificação principal, em seu layout interno atual, compreende hall de entrada e à esquerda sanitário masculino e sala de artes; à direita, sanitário feminino, estúdio e auditório-cinema - setor cultural; já no setor de Transportes, que completa o braço esquerdo do edifício, os usos internos compreendem recepção/estar dos funcionários, sanitários e sala da secretaria. No antigo armazém - edificação secundária - sua distribuição interna é constituída por hall, sala do coordenador/professor, salas de aulas, sala de ensaios gerais e sanitários. Ambas as edificações, térreas, são constituídas por paredes autoportantes, sem a presença de colunas e pilares, somente com reforços estruturais sobressalentes - enrijecedores -, também em alvenaria de tijolos.

O exemplar levantado (Figura 2) - estação de passagem de pequeno porte, com características tipológicas comuns a outras da região - preserva ainda detalhes arquitetônicos originais em seu frontispício, cujo predomínio da linguagem Eclética, com seus elementos simplificados, se faz perceber pela leitura de elementos referentes ao estilo neocolonial - frontão quebrado, cunhais e pilastras bem como dos ornatos em relevo e geometrizados. A inserção dos mesmos na envoltória externa (sem data definida) complementou a arquitetura do simplificado volume, que também passou por alterações de tamanho e a consequente perda das empenas triangulares das laterais. Essa adição de elementos deve-se ao incentivo da então concessionária administradora, influenciada pelos modelos 
arquitetônicos das estações da época, readaptadas ao contexto local. Os detalhes fachadísticos que reforçam o estilo da edificação podem ser ainda observados em seu frontispício principal bastante ornamentado e com contornos trabalhados; simetria - destaque para a entrada elevada; vãos de portas e janelas cuidadosamente emoldurados; ferragens e esquadrias remetendo às peças industrializadas.

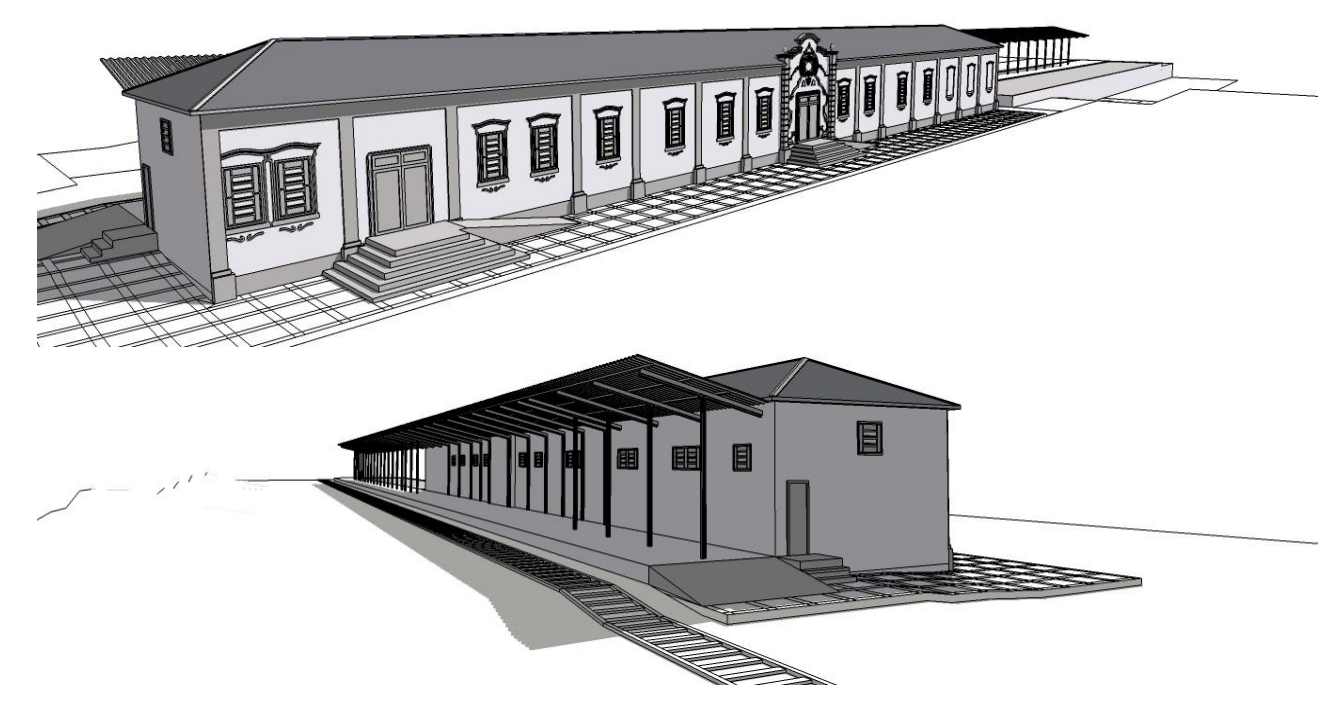

Figura 2. Perspectivas esquemáticas do edifício principal da antiga estação. Fonte: Autores, 2014.

A edificação principal passou, ao longo do tempo, por intervenções e reformas a fim de ampliar suas dependências e dotá-la de infraestrutura demandada com o passar do tempo. A última alteração registrada até o presente momento foi a reforma de fins da década de 90, que serviu para a adequação dos edifícios ao novo uso de Núcleo Cultural, acompanhada pelos profissionais da então administração municipal. As intervenções por que passaram os edifícios - dissociadas do objetivo de restaurá-los de maneira adequada -, em geral não alteraram o invólucro dos mesmos, bem como seus elementos arquitetônicos e decorativos. Porém, no edifício principal, além do aumento de seu comprimento, a fachada voltada para a plataforma sofreu grandes alterações com o fechamento das aberturas de portas e janelas, bem como algumas mudanças do layout interno do mesmo.

Devido à falta de manutenção freqüente, o conjunto da antiga estação sofre com problemas e patologias, identificados a partir de análise visual, como o descaso com relação à vegetação e o acúmulo de lixo no local, jogado principalmente ao longo dos trilhos e das plataformas. A pintura externa apresenta desgaste e algumas pichações. Já a cobertura da plataforma do edifício principal 
apresenta grande quantidade de telhas quebradas. Verificam-se, ainda, algumas readaptações inadequadas, instalações irregulares e sem finalização, o que, no geral, deve-se à falta de planejamento ao se adaptar o edifício aos novos usos.

\section{CONCLUSÃO}

Ponto de chegadas e partidas e de grande movimentação da economia local por muitos anos, a antiga estação ainda é um marco muito forte na paisagem da cidade, cuja preservação deve ser continuada para que se mantenham vivas as origens de seu povo.

Talvez fosse mais preocupante a situação de algumas edificações ferroviárias das cidades da região, as quais se encontram, na melhor das hipóteses, fechadas e em estado de abandono; estando outras em processo de deterioração, condições precárias de preservação e até com partes demolidas. Vale destacar que, não é porque os edifícios que compõem o antigo complexo ferroviário da cidade de Presidente Bernardes - o edifício da estação propriamente dita, de seu antigo armazém e das edificações de uso residencial - estão em uso na atualidade, que se poderá garantir a conservação e a preservação desse patrimônio para a posteridade.

Verifica-se que, como o exemplo de sua última intervenção para a nova destinação, os interesses políticos e de uma minoria privilegiada perpassam o da coletividade, bem como o da necessidade da preservação da memória desse povo. Vale ainda destacar a falta de interesse por parte até de alguma parcela da população que não tem a real dimensão do valor desse exemplar material ainda existente. Contudo existe grande número de pessoas que - algumas até mesmo não sabendo o porquê - considera a antiga Estação como de grande valor ainda hoje. Essas edificações, definidoras e constituintes da paisagem urbana são de vital importância para a cidade contemporânea.

Este apreço pelo material que parece, às vezes, até representar um saudosismo exagerado é, sobretudo, justificável. Ademais, o que deve valer são a preservação e a manutenção desta história concreta e simbólica - da qual somos frutos e, principalmente, somos os seus continuadores. Como meio de assegurar a preservação continuada do mesmo ao longo dos anos, tendo em vista o resgate e a manutenção da memória individual e coletiva das pessoas, o inventário final poderá servir de instrumento para incitar a proposta de tombamento pelos órgãos competentes, primeiramente a nível municipal e, por conseguinte, estadual - CONDEPHAAT ${ }^{2}$.

\footnotetext{
${ }^{2} \mathrm{O}$ Conselho de Defesa do Patrimônio Histórico Arqueológico, Artístico e Turístico tem a função de proteger, valorizar e divulgar o patrimônio cultural no Estado de São Paulo. Governo do Estado - Secretaria da Cultura (http://www.cultura.sp.gov.br) 


\section{REFERÊNCIAS}

SÃO PAULO, PRESIDENTE BERNARDES. Decreto n. 1965/1998. Dispõe sobre a desapropriação de imóvel urbano pertencente anteriormente à Ferrovia Paulista S/A para integrar os bens de domínio público da municipalidade. De 29 de Junho de 1998.

SÃO PAULO, PRESIDENTE BERNARDES. Prefeitura Municipal (website). Disponível em: http://www.presidentebernardes.sp.gov.br/historia.html/. Acesso em 21 de fevereiro de 2014.

BEM, S. F. Contribuições para estudos das estações ferroviárias paulistas. FAU-USP, 1998 / pp. 20.

DEMCZUK, P. G.; MONASTIRSKY, L. B. Ferrovia e memória: reflexões sobre a ferrovia em Irati - PR e seu uso como produto turístico. In: Revista Discente Expressões Geográficas, n. 6, ano VI, P. 71 - 89. Florianópolis, junho 2010.

GIESBRECHT, R. M. Presidente Bernardes (antiga Guarucaia). Disponível em: http://www.estacoesferroviarias.com.br/p/presbernardes.htm. Acesso em 21 de fev. de 2014.

KUHL, B. M. Arquitetura do Ferro e Arquitetura Ferroviária em São Paulo: reflexões sobre a sua preservação. São Paulo: Ateliê Editorial: FAPESP: Secretaria da Cultura, 1998.

LEMOS, C. A. O que é patrimônio histórico. São Paulo: Brasiliense, 2000.

MARQUES, P. P. Técnica, modernização e produção do espaço: um estudo sobre o papel da estrada de ferro nas transformações sócio-espaciais da Zona Alta Sorocabana. Dissertação de Mestrado Faculdade de Filosofia, Letras e Ciências Humanas. USP, São Paulo, 2009.

PASSARELLI, Silvia H. F. Paisagem ferroviária: memória e identidade da metrópole paulistana. In: Revista Exacta, São Paulo, v. 4, n. 2, p.363 - 373, jul/dez, 2006.

PUPIM, R. G. Cidade e território do Oeste Paulista: mobilidade e modernidade nos processos de construção e re-configuração do urbano. Dissertação de Mestrado - Escola de Engenharia de São Carlos da Universidade de São Paulo, São Carlos, 2008.

SANTOS, W. Presidente Bernardes: História de sua Fundação. P. Prudente: [s.n.], 2000. 